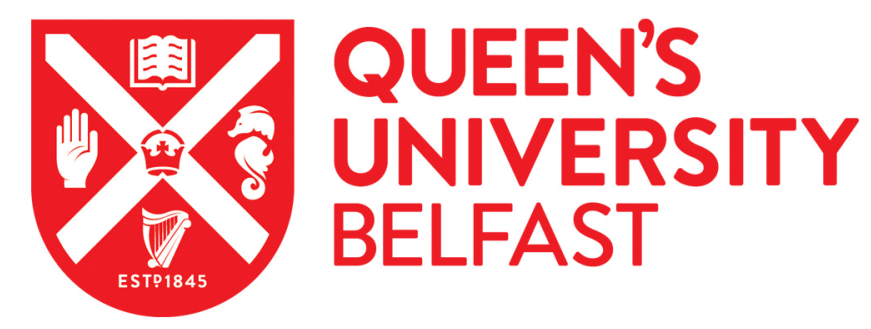

\title{
Economic modelling of antenatal screening and ultrasound scanning programmes for identification of fetal abnormalities
}

Ritchie, K., Bradbury, I., Slattery, J., Wright, D., Iqbal, K., \& Penney, G. (2005). Economic modelling of antenatal screening and ultrasound scanning programmes for identification of fetal abnormalities. British Journal of Obstetrics and Gynaecology, 112 (7)(7), 866-874. https://doi.org/10.1111/j.1471-0528.2005.00560.x

Published in:

British Journal of Obstetrics and Gynaecology

Queen's University Belfast - Research Portal:

Link to publication record in Queen's University Belfast Research Portal

\section{General rights}

Copyright for the publications made accessible via the Queen's University Belfast Research Portal is retained by the author(s) and / or other copyright owners and it is a condition of accessing these publications that users recognise and abide by the legal requirements associated with these rights.

Take down policy

The Research Portal is Queen's institutional repository that provides access to Queen's research output. Every effort has been made to ensure that content in the Research Portal does not infringe any person's rights, or applicable UK laws. If you discover content in the Research Portal that you believe breaches copyright or violates any law, please contact openaccess@qub.ac.uk. 


\title{
Economic modelling of antenatal screening and ultrasound scanning programmes for identification of fetal abnormalities
}

\author{
K. Ritchie, ${ }^{\text {a }}$ I. Bradbury, ${ }^{\text {b }}$ J. Slattery, ${ }^{\text {a }}$ D. Wright, ${ }^{\mathrm{c}}$ K. Iqbal, ${ }^{\mathrm{a}}$ G. Penney ${ }^{\mathrm{d}}$
}

Objective Within the framework of a health technology assessment and using an economic model, to determine the most clinically and cost effective policy of scanning and screening for fetal abnormalities in early pregnancy.

Design A discrete event simulation model of 50,000 singleton pregnancies.

Setting Maternity services in Scotland.

Population Women during the first 24 weeks of their pregnancy.

Methods The mathematical model was populated with data on uptake of screening, prevalence, detection and false positive rates for eight fetal abnormalities and with costs for ultrasound scanning and serum screening. Inclusion of abnormalities was based on the relative prevalence and clinical importance of conditions and the availability of data. Six strategies for the identification of abnormalities prenatally including combinations of first and second trimester ultrasound scanning and first and second trimester screening for chromosomal abnormalities were compared.

Main outcome measures The number of abnormalities detected and missed, the number of iatrogenic losses resulting from invasive tests, the total cost of strategies and the cost per abnormality detected were compared between strategies.

Results First trimester screening for chromosomal abnormalities costs more than second trimester screening but results in fewer iatrogenic losses. Strategies which include a second trimester ultrasound scan result in more abnormalities being detected and have lower costs per anomaly detected.

Conclusions The preferred strategy includes both first and second trimester ultrasound scans and a first trimester screening test for chromosomal abnormalities. It has been recommended that this policy is offered to all women in Scotland.

\section{INTRODUCTION}

Screening for fetal abnormalities is offered to women as part of antenatal care programmes in much of the developed world. Typically, women at higher risk of carrying a fetus with chromosomal and neural tube defects are identified by means of serum markers, ultrasound scanning and/or maternal age. Confirmation of the condition among this high risk group requires a subsequent invasive test. Screening for fetal structural abnormalities, for example, cardiac defects or abdominal wall defects, requires an ultrasound assessment of fetal anatomy usually at around 20 weeks of gestation.

\footnotetext{
${ }^{a}$ NHS Quality Improvement Scotland, Glasgow, UK

${ }^{\mathrm{b}}$ School of Biomedical Sciences, University of Ulster, Coleraine, UK

${ }^{\mathrm{c}}$ Department of Mathematics and Statistics, University of Plymouth, UK

${ }^{\mathrm{d}}$ Scottish Programme for Clinical Effectiveness in Reproductive Health, University of Aberdeen, UK
}

Correspondence: Dr K. Ritchie, NHS Quality Improvement Scotland, Delta House, 50 West Nile Street, Glasgow, G1 2NP, UK.
Screening for chromosomal defects and neural tube defects has been available to all women in Scotland for a number of years. ${ }^{1}$ Ultrasound scanning is offered to all women in Scotland as part of routine antenatal care, however, at present, the timing and purpose of offered ultrasound scans varies considerably between different hospitals. Around half of Scottish women are offered two routine scans during an uncomplicated pregnancy, usually a first trimester booking (dating) scan and a second trimester anomaly scan, with the remainder of women being offered only one scan primarily for dating purposes. ${ }^{2}$

In 2000, Bricker et al. $^{3}$ published a health technology assessment (HTA) which reviewed evidence of clinical and cost effectiveness and of women's views of antenatal ultrasound. The results of the modelling of cost effectiveness in this report showed that one second trimester scan would be the most efficient option. However, the authors of the report apparently endorse the Royal College of Obstetricians and Gynaecologists' recommendation that women are offered a two-stage scan programme comprising a first trimester booking scan and a second trimester anomaly scan. ${ }^{4}$ The report of Bricker et al. was restricted in the sense that no account was taken within the economic modelling of the contribution of serum screening for fetal 
abnormalities. In addition, at the time of publication, there was limited high quality data on the effectiveness of ultrasound measurement of nuchal translucency (NT) as a screening tool for trisomy 21 (Down's Syndrome). Since the publication of the Bricker et al. report, the SURUSS study has reported the results of a large trial of first trimester screening for trisomy 21 and has therefore provided the necessary data that could be used for these purposes. ${ }^{5}$

As part of a HTA carried out by NHS Quality Improvement Scotland to determine the most clinically and cost effective programme of routine ultrasound scanning in early pregnancy, an economic model was constructed to identify the most efficient method for the identification of fetal abnormalities by combinations of screening tests.

Detailed in this report are the development and results of a mathematical model comparing six competing strategies of serum screening and scanning in early pregnancy. The performance of tests was considered in the context of the Scottish population as far as possible. The recommended policy of ultrasound scanning, which was developed from the results of this model and other available evidence, will also be outlined.

\section{METHODS}

Health technology assessment requires detailed appraisal of four main components: clinical effectiveness, cost effectiveness, patients' issues and organisational issues. Evidence is therefore sought and collected from a wide variety of sources including the published scientific literature, unpublished reports, submissions from interested parties, nationally and locally collected statistical data and expert opinion. Evidence is collected and appraised by a multidisciplinary team which includes information scientists, health services researchers, statisticians and health economists and is guided by a group of clinical experts.

Full details of the systematic literature searches carried out for clinical and cost effectiveness and of women's views of ultrasound scanning in pregnancy can be found in the published report of this HTA. ${ }^{2}$

A discrete event simulation model was constructed in $\mathrm{R}^{6}$ to combine the screening performance data with abnormality prevalence and cost data to determine the costs and benefits of six alternative strategies. The model was a simulation study of 50,000 singleton pregnancies (approximately the number of births in Scotland in 2003) with parameters such as maternal age based on the Scottish population.

Table 1 shows the six strategies included in the final version of the model. Three of the strategies are available in Scotland at the time of writing (strategies 4, 5 and 6). Full details of decision pathways for the alternative strategies are given in the report of the HTA. ${ }^{2}$

A restricted number of serious conditions, which can potentially be identified prenatally, were selected for inclusion in the mathematical model used to determine the most appropriate strategy of screening and scanning. The selection of conditions was based on the availability of data on sensitivity of screening techniques, the relative prevalence of conditions and the clinical importance of the conditions (i.e. that women with an affected pregnancy may be offered a termination). The prevalence of conditions was determined primarily using data published by EUROCAT ${ }^{7}$ with Glasgow data selected as representative for Scotland. As EUROCAT reports prevalence at the time of the second trimester scan and anomalies are associated with a higher level of miscarriage, an adjustment was made for those conditions which can be identified in the first trimester. Full details are contained in the HTA report. ${ }^{2}$ The detection rates and false positive rates for included conditions were computed from data from publications identified by the literature search where sufficient information to generate these rates was provided. Prevalence and detection rates of included conditions, together with sources of these rates, are shown in Table 2. The false positive rate for each of the conditions in this table was assumed to be 0 .

It is recognised that in many cases a fetus will be detected as having more than one abnormality. EUROCAT data collected in Glasgow were examined for cases of joint incidence of conditions, however, it was not possible from the data available to determine the joint incidence of the conditions included in this model with the exception of that of trisomy 21 and major cardiac defects. The model was constructed with the assumption that decisions relating to further testing or termination of pregnancy would be based on only one abnormality per fetus. To account for this joint incidence, it was assumed that trisomy 21 would be the

Table 1. Strategies included in the economic model.

\begin{tabular}{llll}
\hline Strategy & First trimester scan & First trimester markers & Second trimester markers \\
\hline 1 & NT & free $\beta$-hCG, PAPP-A & yes \\
2 & NT & free $\beta$-hCG, PAPP-A & no \\
3 & NT & free $\beta$-hCG, PAPP-A & yes \\
4 & NT & free $\beta$-hCG, PAPP-A & n-fetoprotein \\
5 & Booking & - & free $\beta$-hCG, $\alpha$-fetoprotein \\
6 & Booking & - & free $\beta$-hCG, $\alpha$-fetoprotein \\
\hline
\end{tabular}

$\beta$-hCG $=\beta$-human chorionic gonadotrophin; PAPP-A = pregnancy-associated plasma protein-A.

(C) RCOG 2005 BJOG: an International Journal of Obstetrics and Gynaecology 112, pp. 866-874 
Table 2. Ultrasound detection of structural abnormalities.

\begin{tabular}{lccc}
\hline Condition & $\begin{array}{c}\text { Prevalence at } \\
\text { second trimester } \\
\text { per } 10,000\end{array}$ & Detection rate & Source \\
& 8.1 & 0.86 & $8-15$ \\
\hline Anencephaly & & & \\
(at first trimester) & 8.1 & 1.00 & $16-21$ \\
Anencephaly & & & \\
(at second trimester) & 8.8 & 0.80 & $16-21$ \\
Spina bifida & $21.0^{\mathrm{a}}$ & 0.29 & $16-19,22-26$ \\
Cardiac defects & 2.8 & 0.61 & $16-20$ \\
Renal tract defects & 5.8 & 0.77 & $16-20$ \\
Abdominal wall defects & 4.0 & 0.69 & $16-20,27$ \\
Congenital & & & \\
diaphragmatic hernia & & & \\
\hline
\end{tabular}

${ }^{\text {a }}$ Corrected for joint incidence with trisomy 21.

initial finding during a screening programme and therefore the prevalence rate for cardiac defects was reduced by $40 \%$ as this was the approximate joint incidence rate of these conditions observed in the Glasgow EUROCAT data.

The two chromosomal abnormalities included in the mathematical modelling were trisomy 21 (Down's Syndrome) and trisomy 18 (Edwards' syndrome). The SURUSS report provided means, correlation coefficients and standard deviations of the serum markers and NT measurements used for first and second trimester screening at appropriate weeks of pregnancy based on dating scans. This study involved measurement from over 47,000 singleton pregnancies which included around 100 Down's Syndrome pregnancies. There was no intervention following first trimester screening tests reducing the risk of viability bias and the danger of exaggerating the performance of first trimester screening relative to second trimester screening.

Detection and false positive rates were estimated from these parameters for the maternal age distribution of the Scottish population using Monte-Carlo methods. ${ }^{28}$ The prevalence of trisomy 21 was assumed to be 16.9 per 10,000 births and for trisomy 18, 3.8 per 10,000 births. ${ }^{27}$ Within certain limits, the detection rate for these conditions may be chosen by selecting appropriate thresholds for the tests, the benefit of higher detection being offset by higher false positive rates. For the base case the detection rate for trisomy 21 was fixed at $75 \%$ at 20 weeks for each of the screening tests for this condition. False positive rates at this detection rate were computed to be $2.5 \%$ at first trimester screening (10 weeks of gestation) and $6.8 \%$ at second trimester screening.

Detection of trisomy 21 using soft markers at a 20 -week ultrasound scan was modelled by employing the detection and false positive rates published by Winter et al. ${ }^{29}$ It was therefore assumed that for trisomy 21 the detection rate at second trimester ultrasound screening would be $45 \%$ at a $4.9 \%$ false positive rate.

For first trimester screening for trisomy 18, a detection rate of $90 \%$ and false positive rate of $0.5 \%$ as published by Krantz et $a l .^{30}$ was used and a second trimester detection rate of $85 \%$ again at a false positive rate of $0.5 \%$ were provided by Prof. H Cuckle (personal communication, 2003).

Follow up detailed ultrasound scanning is currently offered to women where the fetal NT measurement is above the 95th centile and there is no chromosomal abnormality on the basis that this may allow identification of structural abnormalities, in particular, cardiac defects. However, published data on the detection rates for structural abnormalities by this means are very variable. ${ }^{31-36}$ For the purposes of this model, it was assumed that the detection rate for cardiac defects using raised NT and normal karyotype was $50 \%$ at a $5 \%$ false positive rate which approximates to the findings of the largest of the published studies. ${ }^{33}$

Following a first or second trimester screening test for chromosomal abnormalities, it is assumed that women will be classified as high risk or low risk. In the absence of good data on the Scottish population, it has been assumed for the base case that $50 \%$ of the high risk group accepting an invasive diagnostic test will request chorionic villus sampling (CVS) with the remaining 50\% requesting amniocentesis. Reported fetal loss rates following these procedures vary widely $^{37,38}$ and therefore the values generally accepted by Scottish clinicians of $1 \%$ loss following amniocentesis and $2 \%$ loss following CVS were used in the base case.

Second trimester serum screening for neural tube defects using $\alpha$-fetoprotein was assumed to have a $77 \%$ detection rate at a $3 \%$ false positive rate. ${ }^{39}$ Detection of all conditions suspected at routine scanning was assumed to be confirmed by a detailed ultrasound scan carried out by a consultant obstetrician or radiologist. In the absence of good quality published data on the diagnostic accuracy of a detailed scan, it was assumed that for all conditions, with the exception of spina bifida, the detection rate is $100 \%$ at a $0 \%$ false positive rate. For spina bifida, a $97 \%$ detection rate at a $0 \%$ false positive rate was assumed. ${ }^{40,41}$

Table 3. Acceptance rates for tests and interventions.

\begin{tabular}{lc}
\hline Description & Acceptance rate \\
\hline Acceptance of booking scan & 1.00 \\
Attendance for NT scan and first trimester & 0.76 \\
screen before 14 weeks of gestation & \\
Acceptance of NT scan and first trimester screen & 0.79 \\
Acceptance of second trimester routine anomaly scan & 0.99 \\
Acceptance of second trimester serum screen & 0.76 \\
Acceptance of follow up diagnostic test & 0.77 \\
Acceptance of follow up detailed scan if indicated & 0.99 \\
Elective termination for trisomy 21 & 0.97 \\
Elective termination for trisomy 18 & 0.97 \\
Elective termination for anencephaly & 0.99 \\
Elective termination for spina bifida & 0.88 \\
Elective termination for major cardiac defects & 0.25 \\
Elective termination for major renal tract defects & 0.17 \\
Elective termination for abdominal wall defects & 0.70 \\
Elective termination for congenital & 0.36 \\
diaphragmatic hernia & \\
\hline
\end{tabular}


Table 4. Costs.

\begin{tabular}{|c|c|c|}
\hline & $\begin{array}{l}\text { Mean cost } \\
\text { urban }(£)\end{array}$ & $\begin{array}{l}\text { Mean cost } \\
\text { rural }(\mathfrak{f})\end{array}$ \\
\hline \multicolumn{3}{|l|}{ Informed consent } \\
\hline Booking scan & 7.72 & 8.02 \\
\hline $\begin{array}{l}\text { Booking scan with NT measurement } \\
\text { and first trimester serum screening }\end{array}$ & 13.96 & 8.02 \\
\hline Anomaly scan & 7.72 & 14.40 \\
\hline Detailed diagnostic scan & 13.96 & 14.40 \\
\hline Second trimester serum screening & 7.72 & 8.02 \\
\hline Amniocentesis & 13.96 & 14.40 \\
\hline CVS & 13.96 & 14.40 \\
\hline Termination of pregnancy & 20.20 & 20.90 \\
\hline \multicolumn{3}{|l|}{ Scans } \\
\hline Booking scan & 21.47 & 41.42 \\
\hline Booking scan showing anomalies & 87.95 & 110.55 \\
\hline Booking scan with NT measurement & 32.77 & 53.71 \\
\hline Routine anomaly scan & 31.83 & 52.22 \\
\hline Routine anomaly scan showing anomalies & 98.31 & 121.35 \\
\hline Detailed scan & 107.38 & 130.99 \\
\hline \multicolumn{3}{|l|}{ Serum tests } \\
\hline $\begin{array}{l}\text { First trimester serum screening } \\
\text { (PAPP-A and free } \beta-h C G)\end{array}$ & 27.30 & 28.36 \\
\hline $\begin{array}{l}\text { First trimester serum screening } \\
\text { (PAPP-A and free } \beta \text {-hCG) with } \\
\text { second trimester } \alpha \text {-fetoprotein test }\end{array}$ & 48.13 & 49.56 \\
\hline $\begin{array}{l}\text { Second trimester serum screening policy } \\
\text { (double tests, } \alpha \text {-fetoprotein and hCG) }\end{array}$ & 25.08 & 26.09 \\
\hline \multicolumn{3}{|l|}{ Follow up tests and outcomes } \\
\hline Amniocentesis (negative) & 475.40 & 478.23 \\
\hline Amniocentesis (positive) & 518.71 & 523.33 \\
\hline CVS (negative) & 533.90 & 538.82 \\
\hline CVS (positive) & 490.60 & 493.75 \\
\hline First trimester spontaneous miscarriage & 382.00 & 392.80 \\
\hline Second trimester spontaneous miscarriage & 765.60 & 805.40 \\
\hline CVS-related spontaneous miscarriage & 379.60 & 392.00 \\
\hline Amniocentesis-related spontaneous miscarriage & 765.60 & 805.40 \\
\hline Elective termination during first trimester & 263.10 & 267.90 \\
\hline Elective termination during second trimester & 414.28 & 428.80 \\
\hline
\end{tabular}

$\beta$-hCG $=\beta$-human chorionic gonadotrophin; PAPP-A = pregnancyassociated plasma protein-A.

Acceptance rates for screening and follow up tests were determined by surveying the clinical directors of the 22 consultant-led maternity units in Scotland. Respondents were asked to indicate the proportion of women who accept the screening tests and ultrasound scans offered at their unit, the acceptance rate for diagnostic tests, both invasive tests for chromosomal defects and diagnostic ultrasound scans and the number of women who request termination of pregnancy on confirmation of the conditions included in the model. Some responses obtained by this method were based on locally collected data, however, others would appear to have been an estimation made by the clinician completing the questionnaire. Average acceptance rates were computed from responses to this survey and are given in Table 3 . The proportion of women attending prior to 14 weeks was derived from the CUBS study. ${ }^{42}$
Costs to the NHS of ensuring informed consent for each of the offered tests, of ultrasound scans, maternal serum tests, genetic tests and of spontaneous miscarriages and terminations of pregnancy were determined by means of a bottom up approach. Two sets of costs, one for an urban setting and one for a rural setting, were calculated to capture the differences in costs of providing the service in these settings. Different costs between urban and rural areas were determined for overhead costs, travel costs, cost of capital equipment and maintenance of ultrasound machines and costs of inpatient stays. The costs of providing the alternative programmes of screening were calculated assuming an urban/rural population mix of $78 \% / 22 \%$ derived from GRO population data for local authority areas. Full details of the methodology to determine costs will be published separately. A summary of the costs of screening tests and associated procedures is given in Table 4 .

A number of assumptions were made in the base case model when strategies were compared:

- Women who present after 13 completed weeks of gestation will be offered a booking scan (to determine fetal viability and gestational age) and second trimester serum screening in place of NT scanning and first trimester serum screen.

- Any woman offered but not accepting a first trimester screen for chromosomal abnormalities will not subsequently be offered a second trimester screen for these conditions, however, they will still be offered ultrasound scans.

- Each affected fetus will have only one of the included abnormalities.

- All women screening positive for chromosomal abnormalities either at first or second trimester screening will be offered a detailed scan in addition to an invasive diagnostic test.

- Offer of an invasive diagnostic test is based on the pregnancy being categorised as at high or low risk and not more precise estimates of risk.

- A second trimester $\alpha$-fetoprotein test following a first trimester screen for chromosomal abnormalities is for the purpose of assessing risk of spina bifida only.

- The diagnostic test for spina bifida is a detailed ultrasound scan.

- When the follow up diagnostic test is a detailed scan, only one scan is offered.

\section{RESULTS}

None of the six strategies on which we focus in this article included detection of soft markers at second trimester scanning to screen for chromosomal abnormalities. This is because a separate analysis showed this to do more harm than good. From this result, the assessment of risk of trisomy at a second trimester anomaly scan was considered 


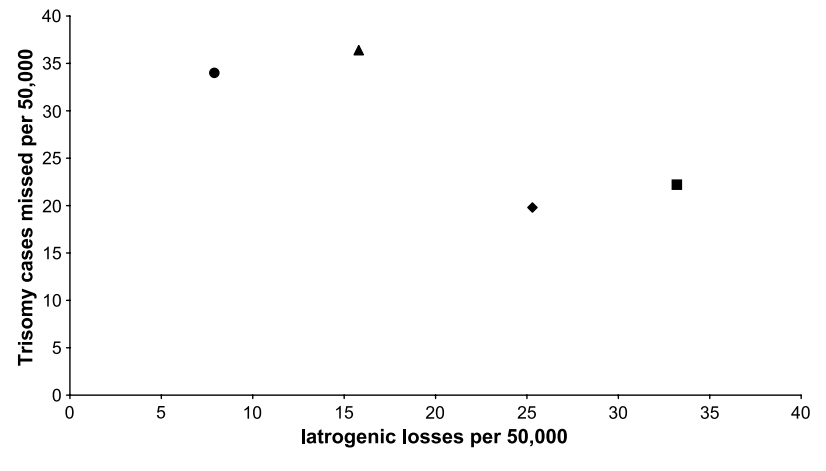

$\bullet$ Strategy $1 \Delta$ Strategy $5 \bullet$ Strategy $1+$ soft markers $\square$ Strategy $5+$ soft markers

Fig. 1. Results of adding screening for chromosomal abnormalities using soft markers.

to be ill-advised as more iatrogenic losses than detected cases of trisomy will result and therefore in the further analysis presented here it was assumed that there is no assessment of risk of chromosomal abnormality at the second trimester anomaly scan. The reason for this is illustrated in Fig. 1 where the results of two different strategies for screening for chromosomal abnormalities are shown. In this figure, Strategy 1, which includes a first trimester screen for chromosomal abnormalities, is compared with Strategy 5, where a second trimester serum screening test is offered. In addition, both strategies include a second trimester anomaly scan. Inclusion of a further screen for trisomy at the anomaly scan, using soft markers, will reduce the number of live born cases of undetected trisomy but will increase greatly the number of iatrogenic losses-if Strategy 1 is used the iatrogenic loss rate will triple.
The results of the model of costs and benefits for all strategies are summarised in Table 5. It can be observed that Strategy 3, the most costly strategy, will result in the fewest number of live born false negative cases of abnormality and the fewest cases of iatrogenic loss resultant from invasive follow up tests. The least costly of the strategies, Strategy 6, will result in a much greater number of false negative cases and also in almost twice as many cases of iatrogenic loss. A first trimester screening test for trisomy will result in around half as many iatrogenic losses as a second trimester screen at a comparable detection rate. A second trimester anomaly scan will result in the detection of an additional 100 to 120 fetuses with serious abnormalities. Comparison of Strategy 3, which includes an $\alpha$-fetoprotein test in the second trimester, with Strategy 1, in which the only difference is the omission of this $\alpha$-fetoprotein test, shows that an additional four to five cases of spina bifida would be detected at an additional cost of $£ 833,000$ for a population of 50,000 or almost $£ 17$ per woman. This cost reflects the additional costs for the $\alpha$-fetoprotein test and the costs associated with offering a detailed ultrasound scan for diagnostic purposes for a large number of false positive cases.

Table 6 shows the costs of each of the strategies per woman and per anomaly detected and the incremental cost effectiveness ratio (ICER). The ICER was computed by dividing the difference in cost between that of each strategy and the cheapest strategy (Strategy 6) by the difference in the number of abnormalities detected by the two strategies. The ICER therefore gives the additional cost per additional abnormality detected.

Although the cost of screening for chromosomal abnormalities by a first trimester test (Strategies 1 and 2) costs

Table 5. Summary of results of modelling costs and benefits.

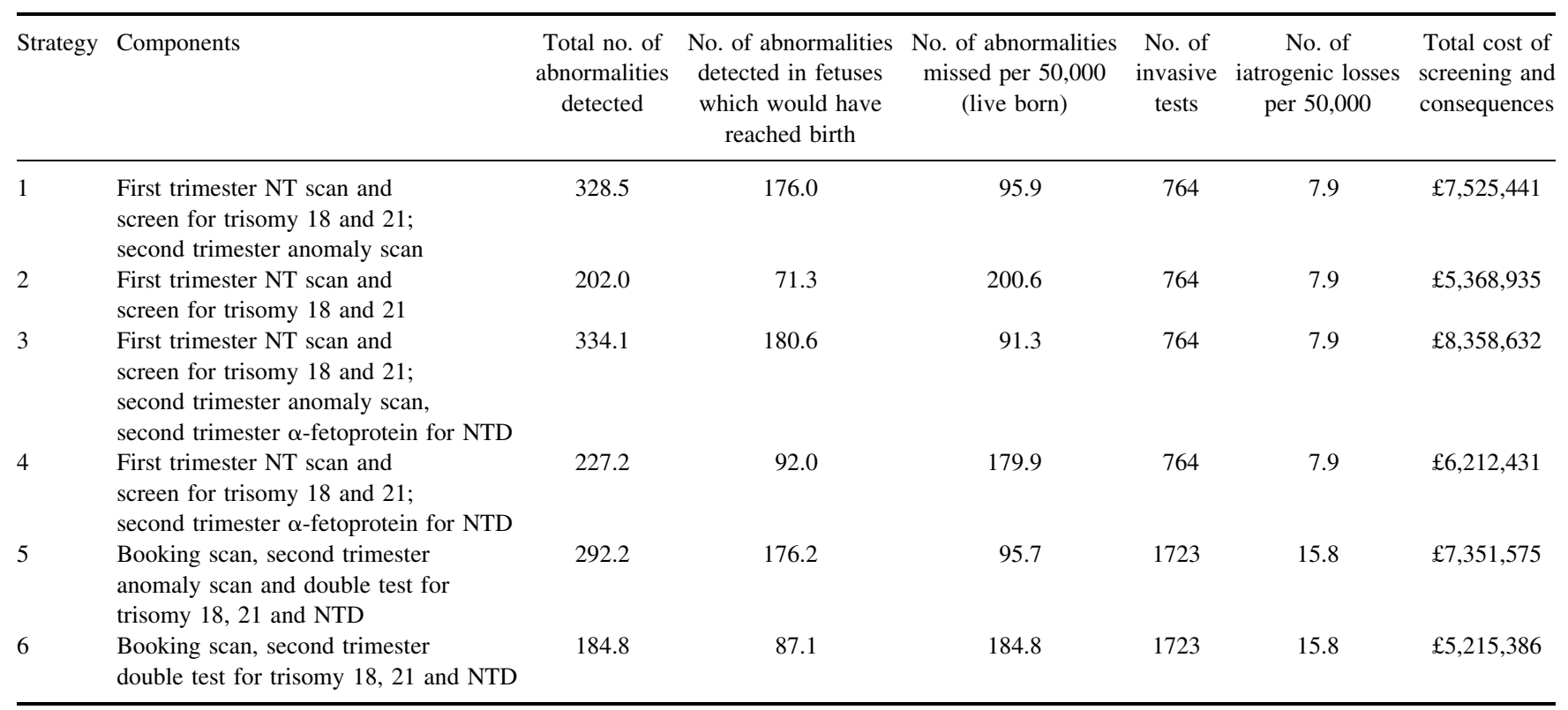

$\mathrm{NTD}=$ neural tube defects 
Table 6. Cost of screening per woman and per anomaly detected.

\begin{tabular}{|c|c|c|c|c|c|c|}
\hline Strategy & Components & $\begin{array}{l}\text { Total costs of } \\
\text { screening and } \\
\text { consequences } \\
\text { per woman }\end{array}$ & $\begin{array}{l}\text { Total cost of } \\
\text { screening and } \\
\text { consequences }\end{array}$ & $\begin{array}{l}\text { Total no. of } \\
\text { abnormalities } \\
\text { detected }\end{array}$ & $\begin{array}{l}\text { Total costs } \\
\text { (screening and } \\
\text { consequences) per } \\
\text { anomaly detected }\end{array}$ & $\begin{array}{l}\text { Incremental cost } \\
\text { effectiveness ratio }\end{array}$ \\
\hline 6 & $\begin{array}{l}\text { Booking scan, second trimester } \\
\text { double test for trisomy } 18,21 \text { and NTDs }\end{array}$ & $£ 104$ & $£ 5,215,386$ & 184.8 & $£ 28,222$ & reference value \\
\hline 1 & $\begin{array}{l}\text { First trimester NT scan and } \\
\text { screen for trisomy } 18 \text { and } 21 ; \\
\text { second trimester anomaly scan }\end{array}$ & $£ 151$ & $£ 7,525,441$ & 328.5 & $£ 22,909$ & $£ 4790$ \\
\hline 2 & $\begin{array}{l}\text { First trimester NT scan and } \\
\text { screen for trisomy } 18 \text { and } 21\end{array}$ & $£ 107$ & $£ 5,368,935$ & 202.0 & $£ 26,574$ & $£ 8927$ \\
\hline 5 & $\begin{array}{l}\text { Booking scan, second trimester } \\
\text { anomaly scan and double test for } \\
\text { trisomy } 18,21 \text { and NTDs }\end{array}$ & $£ 147$ & $£ 7,351,575$ & 292.2 & $£ 25,162$ & $£ 17,525$ \\
\hline 4 & $\begin{array}{l}\text { First trimester NT scan and } \\
\text { screen for trisomy } 18 \text { and } 21 ; \\
\text { second trimester } \alpha \text {-fetoprotein for NTD }\end{array}$ & $£ 124$ & $£ 6,212,431$ & 227.2 & $£ 27,339$ & $£ 33,472$ \\
\hline 3 & $\begin{array}{l}\text { First trimester NT scan and } \\
\text { screen for trisomy } 18 \text { and } 21 ; \\
\text { second trimester anomaly scan, } \\
\text { second trimester } \alpha \text {-fetoprotein for NTD }\end{array}$ & $£ 167$ & $£ 8,358,632$ & 334.1 & $£ 25,017$ & $£ 148,784$ \\
\hline
\end{tabular}

$\mathrm{NTD}=$ neural tube defects.

around £11 per woman more than the second trimester double test (Strategies 5 and 6), the reduction in the number of false positive cases results in the additional cost per women for screening and consequences to be reduced to around $£ 4$ per woman. A second trimester anomaly scan costs $£ 42$ per woman, however, each of the strategies, which includes an anomaly scan, has a lower cost per anomaly detected than the corresponding strategy without the anomaly scan. It can be observed that Strategy 1, which includes a first trimester screen for abnormalities and a second trimester anomaly scan, has the lowest cost per anomaly detected when compared with the other five competing strategies.

When the ICER is considered using Strategy 6 as the reference value, it can be observed that Strategy 1 is the next least expensive and is one of the strategies with the lower rate of invasive tests and associated iatrogenic losses.

A number of the assumptions made in the base case model were tested in a series of sensitivity analyses. In the base case, a 75\% detection rate at the second trimester was selected in light of the recent NICE guidelines indicating that by April 2007 women should be offered a screening test with a detection rate above $75 \%$ and a false positive rate below 3\%. ${ }^{43}$ To assess the effect of varying the detection rate, the number of live false negative cases and iatrogenic losses was compared for Strategies 1 and 5. Increasing the detection rate to $80 \%$ would reduce the number of live false negative cases from 34 to 30.9 and 36.4 to 33.5 for Strategies 1 and 5, respectively, but would increase the number of iatrogenic losses from 7.9 to 17.8 and 15.8 to 21.7 , respectively. Use of a fixed risk cutoff level of 1 in 250, as is currently used in Scotland for both first and second trimester screening, will result in fewer false negative cases of trisomy when first trimester screening rather than second trimester screening is offered (i.e. 29 and 33.6 cases for Strategies 1 and 5, respectively). However, the iatrogenic loss rates will be equal for both strategies at 21.7 cases.

It has been assumed in the base case that first trimester screening would be performed, when requested, at 10 weeks of gestation. If screening occurs later in the first trimester, the performance of the screening test depends on whether the appropriate risk model is used according to gestational age. Using week 10 parameters to determine the risk of a 13 -week fetus would result in a reduction in the false positive rate, therefore reducing the number of iatrogenic losses from 7.9 to 3.9 , but also reducing the detection rate resulting in an increase in the number of live born cases of undetected chromosomal abnormality from 34 to 41.4. Use of the correct parameters for a 13-week fetus will restore the test performance.

There is substantial uncertainty surrounding the number of women in Scotland who would request CVS as the diagnostic test for chromosomal abnormality and the number who would prefer to have a later, but potentially less risky, amniocentesis. In the base case, we have assumed that equal numbers of women requesting the diagnostic test will opt for these alternatives. To test the effect of a change in this proportion, alternative scenarios where all women opt for one or other of the tests have been modelled. In a strategy with first trimester screening, when all women request CVS and the fetal loss rate is $2 \%$, the number of iatrogenic losses, at 13.8 for a population of 50,000 pregnancies, would be slightly lower than the 15.8 that would be seen if second trimester screening was offered. From these 
results, it can be concluded that first trimester screening results in fewer iatrogenic losses, even if all screenpositive women opt for CVS with an associated loss rate of $2 \%$.

\section{DISCUSSION AND CONCLUSION}

From the results of the mathematical model presented here, it has been shown that a prenatal screening strategy which includes a first trimester test for chromosomal abnormalities and a second trimester ultrasound scan will identify around $65 \%$ of fetal abnormalities and would result in around eight iatrogenic losses in a population of 50,000 women. By comparison, the programme of screening currently offered to around half of Scottish women, which includes a first trimester dating scan and a second trimester double serum screen, would identify only $32 \%$ of major fetal abnormalities and would result in around 16 iatrogenic losses. There are additional financial costs associated with offering the preferred strategy, specifically an additional $£ 4$ per woman for a first trimester test for chromosomal abnormalities and an additional $£ 42$ per woman for a second trimester anomaly scan. However, the benefits, in addition to the increased number of abnormalities detected and the reduction in iatrogenic losses, would be earlier detection of chromosomal abnormalities and a reduction in the number of invasive diagnostic tests both of which are likely to be valued by women.

A disadvantage of earlier screening for chromosomal abnormalities is that a number of cases of abnormality will be detected at the first trimester that would be destined not to survive to the time of second trimester testing. Therefore, a number of women who may have had a spontaneous miscarriage between the first and second trimester would undergo diagnostic testing and possibly also elected to have a termination of pregnancy.

The inclusion of a second trimester $\alpha$-fetoprotein test for identification of pregnancies at high risk of spina bifida, in addition to a first trimester screening test and a second trimester anomaly scan, would result in around five additional cases of spina bifida being detected at a cost of around 1000 false positive tests with the associated costs in both resources and parental anxiety. This strategy is by far the most expensive of those compared in this study as illustrated by the incremental cost effectiveness analysis. It is unusual in a screening programme to have two separate tests for one condition and when anomaly scanning is the only screening test for this condition, detection rates may increase to close to the $97 \%$ detection rate for diagnostic scans following a high $\alpha$-fetoprotein result.

In this modelling exercise, only conditions considered sufficiently serious to warrant offer of a termination of pregnancy were included. No attempts were made to include the benefits of recognition of the considerable number of less serious conditions which may be identified during a second trimester scan. The difficulties of extending a model to include such conditions are threefold. Firstly, epidemiological data for many less serious conditions are less readily available. Secondly, false positive rates for more minor conditions are likely to be higher than major structural abnormalities and these rates are rarely systematically reported, therefore the costs, both financial and in parental anxiety, will be difficult to quantify. Thirdly, the benefits of detection of most minor fetal abnormalities are as yet unquantified. We have assumed in the model presented here that parents value information on major fetal abnormalities in that it allows choices to be made regarding continuation of the pregnancy. As the relative value of knowledge of minor abnormality prenatally as opposed to at birth is unknown, we have not included such conditions in this model.

The study has a number of other limitations. As has already been said, the number of false positives following a second trimester ultrasound scan is rarely reported in the published literature. Rather the number of false positive cases that reach birth or termination of pregnancy is given. The false positive rate will have a considerable effect on the number of follow up investigations and therefore the costs of the competing strategies.

The SURUSS parameter estimates we used tend to give poorer performance in first trimester screening than those taken from studies with intervention in the first trimester. For example, in the large study of Nicolaides et al., ${ }^{44}$ the median value of NT was 2.27 , compared with 1.96 obtained from SURUSS. Thus, in terms of the relative benefit of first trimester screening, the choice of SURUSS parameter estimates is conservative when contrasted with the evidence from larger intervention studies.

Two competing strategies for identification of chromosomal abnormalities have been included in the model presented. These two strategies are currently the only tests available in Scotland. A number of other alternatives could have been included, for example, triple or quadruple marker serum screening or integrated testing, where results of a first and a second trimester test are combined. Inclusion of alternative screening strategies may have altered the conclusions in favour of one of these alternatives to a first trimester test for chromosomal abnormalities and a second trimester anomaly scan. However, this assessment was conducted specifically for the purposes of making policy recommendations for Scotland where currently no centres are currently offering triple or quadruple marker screening or integrated testing. In addition, it should be noted that the UK National Screening Committee is at present addressing the continuing debate surrounding the reliability of inhibin as a marker for Down's Syndrome in the clinical setting by the commissioning of a pilot study. There would be further difficulties associated with the inclusion of a test such as the integrated test in that no data are available on the uptake of such tests by the Scottish population. Uptake rates for first trimester screening for 
chromosomal abnormalities data from the CUBS study ${ }^{42}$ were around $80 \%$. This should be compared with the $97.5 \%$ acceptance rate reported in the study of Spencer et $a l .{ }^{45}$ among women in the Southeast of England.

It was clear from the results of the model that assessment of risk of trisomy at the second trimester anomaly scan following a previous screening, either in the first or second trimester, would result in an increase in the number of cases detected but at a cost of large number of iatrogenic losses. It should be noted that it was assumed that all women requesting this scan would have the assessment of trisomy risk carried out. In the model it has been assumed that $99 \%$ of women will request an anomaly scan compared with $76 \%$ requesting second trimester serum screening. Therefore, those cases of trisomy missed at the previous screening opportunity among women who opted to avoid serum screening for trisomy would be included in the subsequent assessment of trisomy risk at the anomaly scan. It could be argued that this is inappropriate and that such women would be likely also to opt out of the anomaly scan if they were aware that it would also be used to assess trisomy risk. However, rather than attempting to construct a complex and hypothetical model of women's behaviour, it is more appropriate to recommend that further clinical evidence is needed to demonstrate the value of using soft markers to assess trisomy risk in low risk pregnancies.

In this study, we have conducted a cost consequence analysis with costs limited to those of the health care provider to the point of delivery (or termination of the pregnancy) and have not attempted to determine the costs incurred post-delivery. The health care and societal costs associated with the care of false negative live born children with abnormalities would be considerable and therefore the inclusion of such costs would almost certainly have resulted in those strategies that identify the greatest number of abnormalities, and therefore resulting in the greatest number of terminations of pregnancy, appearing to be the most cost effective.

A cost benefit analysis was not thought to be an appropriate approach in this assessment as there are considerable difficulties in assigning appropriate utilities to the information resulting from screening and diagnostic tests used antenatally. Harris et $a l .{ }^{46}$ employed utilities in decision tree modelling for prenatal screening for trisomy 21 and concluded that invasive diagnostic testing for all women is effective irrespective of the high number of iatrogenic losses that would result. This counterintuitive finding may be particular to the group participating in the study, the comparator chosen or the quality of information given to women at the time of the interviews used to derive the utility scores. A second consideration for cost benefit analysis is how to extend quantitative assessment of the benefits of prenatal diagnosis beyond those experienced by the mother. It is unclear how this can be achieved. For these reasons, the results presented here are in the form of a cost consequence analysis which will necessarily contain an element of subjectivity.

Therefore, although it is acknowledged that an alternative approach to the economic evaluation used in this project may have resulted in a different ordering of the strategies, the difficulties in quantifying all the health care and societal costs (financial and other costs including those such as parental anxiety or iatrogenic loss) and all the benefits of antenatal screening are justification for the approach described here.

This mathematical model was developed as part of a HTA which also considered the needs and preferences of pregnant women and the organisational issues surrounding provision of routine ultrasound scanning before 24 weeks of pregnancy. These other areas included in the assessment provided evidence that women enjoy having scans and would welcome the opportunity for earlier detection of chromosomal abnormalities, but the purpose of scans is not always clear to women. Also it was found that there is considerable variation in the programme of scanning across Scotland, in clinical practice between units, in the training of staff and the equipment used. On considering all the evidence together with the findings of the model, it has been recommended that the preferred strategy from the model (i.e. two ultrasound scans, one in the first trimester, which could include NT measurement for risk assessment for chromosomal abnormalities, and one in the second trimester for identification of structural abnormalities) should be offered to all women in Scotland. This programme of scanning must, however, be provided in such a way that women are clear that scanning is not mandatory and to allow sufficient time and information for women to make informed decisions at each stage in their antenatal care.

\section{References}

1. Scottish Executive Health Department. Antenatal Screening for Down's Syndrome and Neonatal Screening for Phenylketonuria and Congenital Hypothyroidism. HDL (2001), 34. Edinburgh: SEHD, 2001.

2. Ritchie K, Boynton J, Bradbury I, et al. Routine ultrasound scanning before 24 weeks of pregnancy. Health Technology Assessment Report 5. Glasgow: NHS Quality Improvement Scotland, 2004.

3. Bricker L, Garcia J, Henderson J, et al. Ultrasound screening in pregnancy: a systematic review of the clinical effectiveness, costeffectiveness and women's views. Health Technol Assess 2000;4(16).

4. Royal College of Obstetricians and Gynaecologists. Routine Ultrasound Screening in Pregnancy: Protocol, Standards and Training. London: RCOG Press, 2000.

5. Wald N, Rodeck C, Hackshaw AK, Walters J, Chitty L, Mackinson AM. First and second trimester antenatal screening for Down's syndrome: the results of the serum, urine, and ultrasound screening study (SURUSS). Health Technol Assess 2003;7(11).

6. R Development Core Team. $R$ Language Definition: Version 1.8.0 [Draft]. Vienna, Austria: R Foundation for Statistical Computing, 2003.

7. Eurocat Working Group. Eurocat Report 8: Surveillance of Congenital Anomalies 1980-1999. Newtonabbey, Co Antrim: University of Ulster, 2002. 
8. Carvalho $\mathrm{MH}$, Brizot ML, Lopes LM, Chiba $\mathrm{CH}$, Miyadahira S, Zugaib M. Detection of fetal structural abnormalities at the $11-$ 14 week ultrasound scan. Prenat Diagn 2002;22(1):1-4.

9. Chatzipapas IK, Whitlow BJ, Economides DL. The 'Mickey Mouse' sign and the diagnosis of anencephaly in early pregnancy. Ultrasound Obstet Gynecol 1999;13(3):196-199.

10. D'Ottavio G, Mandruzzato G, Meir YJ, et al. Comparison of first and second trimester screening for fetal anomalies. Ann N Y Acad Sci 1998;847:200-209.

11. Drysdale K, Ridley D, Walker K, Higgins B, Dean T. First-trimester pregnancy scanning as a screening tool for high-risk and abnormal pregnancies in a district general hospital setting. J Obstet Gynaecol 2002;22(2):159-165.

12. Hernadi L, Torocsik M. Screening for fetal anomalies in the 12 th week of pregnancy by transvaginal sonography in an unselected population. Prenat Diagn 1997;17(8):753-759.

13. Johnson SP, Sebire NJ, Snijders RJ, Tunkel S, Nicolaides KH. Ultrasound screening for anencephaly at 10-14 weeks of gestation. Ultrasound Obstet Gynecol 1997;9(1):14-16.

14. Taipale P, Ammala M, Salonen R, Hiilesmaa V. Learning curve in ultrasonographic screening for selected fetal structural anomalies in early pregnancy. Obstet Gynecol 2003;101(2):273-278.

15. Whitlow BJ, Chatzipapas IK, Lazanakis ML, Kadir RA, Economides DL. The value of sonography in early pregnancy for the detection of fetal abnormalities in an unselected population. Br J Obstet Gynaecol 1999;106(9):929-936.

16. Crane JP, LeFevre ML, Winborn RC, et al. A randomized trial of prenatal ultrasonographic screening: impact on the detection, management, and outcome of anomalous fetuses. Am J Obstet Gynecol 1994;171(2):392-399.

17. Levi S, Schaaps JP, De Havay P, Coulon R, Defoort P. End-result of routine ultrasound screening for congenital anomalies: the Belgian Multicentric Study 1984-92. Ultrasound Obstet Gynecol 1995;5(6): 366-371.

18. Stefos T, Plachouras N, Sotiriadis A, et al. Routine obstetrical ultrasound at 18-22 weeks: our experience on 7236 fetuses. J Matern Fetal Med 1999;8(2):64-69.

19. Sahinoglu Z, Uludogan M, Gurbuz A, Kol E. Prenatal detection of fetal anomalies by ultrasonography in the second trimester: our first results from Turkey. Prenat Neonat Med 2001;6(2):103-111.

20. Anderson N, Boswell O, Duff G. Prenatal sonography for the detection of fetal anomalies: results of a prospective study and comparison with prior series. Am J Roentgenol 1995;165(4):943-950.

21. Girish GS, Singh H. Prenatal diagnosis of neural tube defects. Med J Armed Forces India 2001;57(2):126-128.

22. Todros T, Faggiano F, Chiappa E, Gaglioti P, Mitola B, Sciarrone A. Accuracy of routine ultrasonography in screening heart disease prenatally. Gruppo Piemontese for Prenatal Screening of Congenital Heart Disease. Prenat Diagn 1997;17(10):901-906.

23. Buskens E, Grobbee DE, Frohn-Mulder IM, et al. Efficacy of routine fetal ultrasound screening for congenital heart disease in normal pregnancy. Circulation 1996;94(1):67-72.

24. Hafner E, Scholler J, Schuchter K, Sterniste W, Philipp K. Detection of fetal congenital heart disease in a low-risk population. Prenat Diagn 1998;18(8):808-815.

25. Ott WJ. The accuracy of antenatal fetal echocardiography screening in high- and low-risk patients. Am J Obstet Gynecol 1995;172(6):1741 1749 .

26. Rustico MA, Benettoni A, D’Ottavio G, et al. Fetal heart screening in low-risk pregnancies. Ultrasound Obstet Gynecol 1995;6(5):313-319.

27. Guariglia L, Rosati P. Transvaginal sonographic detection of embryonic-fetal abnormalities in early pregnancy. Mech Dev 2000; 96(2):328-332.
28. Wright D, Bradbury I, Benn P, Cuckle H, Ritchie K. Contingen screening for Down's syndrome is an efficient alternative to nondisclosure sequential screening. Prenatal Diagn 2004;24(10):762-766.

29. Winter TC, Uhrich SB, Souter VL, Nyberg DA. The 'genetic sonogram': comparison of the index scoring system with the ageadjusted US risk assessment. Radiology 2000;215(3):775-782.

30. Krantz DA, Hallahan TW, Orlandi F, Buchanan P, Larsen Jr JW, Macri JN. First-trimester down syndrome screening using dried blood biochemistry and nuchal translucency. Obstet Gynecol 2000;96(2): 207-213.

31. Bilardo CM, Pajkrt E, de Graaf I, Mol BW, Bleker OP. Outcome of fetuses with enlarged nuchal translucency and normal karyotype. Ultrasound Obstet Gynecol 1998;11(6):401-406.

32. Hafner E, Schuchter K, Philipp K. Screening for chromosomal abnormalities in an unselected population by fetal nuchal translucency. Ultrasound Obstet Gynecol 1995;6(5):330-333.

33. Hyett J, Perdu M, Sharland G, Snijders R, Nicolaides KH. Using fetal nuchal translucency to screen for major congenital cardiac defects at 10-14 weeks of gestation: population based cohort study. BMJ 1999; 318(7176): $81-85$

34. Josefsson A, Molander E, Selbing A. Nuchal translucency as a screening test for chromosomal abnormalities in a routine first trimester ultrasound examination. Acta Obstet Gynecol Scand 1998; 77(5):497_ 499.

35. Mavrides E, Cobian-Sanchez F, Tekay A, et al. Limitations of using first-trimester nuchal translucency measurement in routine screening for major congenital heart defects. Ultrasound Obstet Gynecol 2001; 17(2): $106-110$

36. Michailidis GD, Economides DL. Nuchal translucency measurement and pregnancy outcome in karyotypically normal fetuses. Ultrasound Obstet Gynecol 2001;17(2):102-105.

37. Wald N, Kennard A. Routine ultrasound scanning for congenital abnormalities. Ann N Y Acad Sci 1998;847:173-180.

38. Heckerling PS, Verp MS. Amniocentesis or chorionic villus sampling for prenatal genetic testing: a decision analysis. J Clin Epidemiol 1991;(44):657-670.

39. Boyd PA, Wellesley DG, De Walle HE, et al. Evaluation of the prenatal diagnosis of neural tube defects by fetal ultrasonographic examination in different centres across Europe. J Med Screen 2000; 7(4):169-174

40. Cuckle HS. Screening for neural tube defects. In: Bock G, Marsh J, editors. Neural Tube Defects. Chichester: Wiley, 1995:253-269.

41. Lennon CA, Gray DL. Sensitivity and specificity of ultrasound for the detection of neural tube and ventral wall defects in a high-risk population. Obstet Gynecol 1999;94(4):562-566.

42. Crossley JA, Aitken DA, Cameron AD, McBride E, Connor JM Combined ultrasound and biochemical screening for Down's syndrome in the first trimester: a Scottish multicentre study. $\mathrm{Br} J$ Obstet Gynaecol 2002;109(6):667-676.

43. National Institute for Clinical Excellence. Antenatal Care: NICE Guideline. London: NICE, 2003.

44. Nicolaides KH, Snijders RJ, Cuckle HS. Correct estimation of parameters for ultrasound nuchal translucency screening. Prenatal Diagnosis 1998;18(5):519-523.

45. Spencer K, Spencer CE, Power M, Moakes A, Nicolaides KH. One stop clinic for assessment of risk for fetal anomalies: a report of the first year of prospective screening for chromosomal anomalies in the first trimester. Br J Obstet Gynaecol 2000;107(10):1271-1275.

46. Harris R, Washington AE, Nease R, Kuppermann M. Cost utility of prenatal diagnosis and the risk-based threshold. Lancet 2004;363: $276-282$.

Accepted 12 October 2004 